Revista Tecné, Episteme y Didaxis: TED. Año 2014, Número Extraordinario. ISSN Impreso: 0121-3814, ISSN web: 2323-0126

Memorias, Sexto Congreso Internacional sobre Formación de Profesores de Ciencias. 08 al 10 de octubre de 2014, Bogotá

\title{
Produção de documentário com alunos da educação de jovens e adultos: uma proposta metodológica para elaboração de material didático includente
}

\author{
Sousa Cinthia Aparecida. Dias Cassiano Karla Ferreira'
}

Categoria 2: Trabalho de investigação.

\section{Resumo}

Apesar de a educação brasileira ser constituída a partir de contribuições de diversos grupos sociais e culturais, na sociedade vários sujeitos são excluídos dos direitos às condições de vida digna, como o acesso à escola e seus benefícios. Nesse contexto surge a Educação de Jovens e Adultos (EJA) como uma modalidade reparativa construída por suas particularidades. Diante disso, propõe-se produzir um documentário com alunos da EJA a fim de produzir e/ou identificar dados para elaborar um material didático com características inclusivas. Trata-se de uma pesquisa qualitativa caracterizada como um estudo de caso devido às particularidades do estudo em questão. Foram identificadas categorias que expressam ideias sobre: a afirmação da importância da ciência; a visualização de processo químico e utilização de produtos químicos / substâncias; a relação entre a mudança de vida das pessoas com a indústria química; a relação entre a mudança do meio ambiente com a indústria química; a convergência de conceitos químicos e a visão de composição do mundo. Como conclusão preliminar é possível notar que a produção de documentário pode apreender concepções prévias dos alunos da EJA possibilitando informações iniciais de conceitos a serem trabalhados em material didático específico para esse público.

\section{Palavras-chave}

Exclusão-inclusão, EJA, Documentário, material Didático Includente.

\section{Objetivo}

Produzir um documentário com alunos da EJA para desenvolver metodologia de elaboração de Material Didático Includente (MDI) por meio da utilização de dados construídos pelas falas dos próprios futuros leitores. Em uma etapa posterior a esse trabalho, o objetivo será elaborar um material didático de

\footnotetext{
1 Instituto Federal de Goiás - karladias.cassiano@gmail.com
} 
Revista Tecné, Episteme y Didaxis: TED. Año 2014, Número Extraordinario. ISSN Impreso: 0121-3814, ISSN web: 2323-0126

Memorias, Sexto Congreso Internacional sobre Formación de Profesores de Ciencias. 08 al 10 de octubre de 2014, Bogotá

Química que tente incluir em processos de ensino os sujeitos da EJA a partir de suas vivências registrados nesse documentário.

\section{Marco teórico}

A história da educação no Brasil apresenta indícios que apontam para a criação e o fortalecimento de políticas educacionais ampliadoras das desigualdades entre a elite e os filhos da classe trabalhadora o que reproduz processos excludentes de alguns sujeitos no campo educacional.

Nesse contexto, a ideia de exclusão pode ser designada como fenômeno do conjunto de desigualdades sociais, miséria, injustiça, exploração social e econômica, marginalização social, entre outras significações.

Sobre os processos excludentes que ocorrem na sociedade moderna, Santos (2010, págs.31 e 32) afirma que:

O pensamento moderno ocidental é um pensamento abissal. Consiste num sistema de distinções visíveis e invisíveis, sendo que as invisíveis sustentam as visíveis. As distinções invisíveis são estabelecidas através de linhas radicais que dividem a realidade social em dois universos distintos: o universo deste lado da linha e o universo do outro lado da linha (SANTOS, 2010, págs.31 e 32).

Na coexistência provocada pela divisão, um lado desaparece como se não existisse, predominando somente o outro lado. O pensamento abissal moderno caracteriza-se pela sua capacidade de produzir e radicalizar distinções, e nesse momento de radicalização pode acontecer a não "consideração do outro" ou a descaracterização da outridade, para Dussel (2005). O outro, em sua total exterioridade, pode ser considerado o não-ser. O Ser é considerado o fundamento do sistema e do mundo cotidiano. No entanto, há realidade para além do ser, para além do sistema e, por isso, o outro é considerado como não-ser.

Nesse contexto, os alunos da EJA podem ser considerados como os oprimidos e o sistema como opressor de acordo com as ideias de Freire (2011), sendo que a maioria dos oprimidos se adapta à condição de não liberdade, acomodando tudo aquilo que lhes são impostos socialmente e culturalmente pela sociedade na figura da escola. É coerente dizer que além do horizonte do ser, o outro é o bárbaro e na defesa de Ginés (1967, pág. 85 apud DUSSEL, 2010, pág. 355): 
Revista Tecné, Episteme y Didaxis: TED. Año 2014, Número Extraordinario. ISSN Impreso: 0121-3814, ISSN web: 2323-0126

Memorias, Sexto Congreso Internacional sobre Formación de Profesores de Ciencias. 08 al 10 de octubre de 2014, Bogotá

Será sempre justo e conforme ao direito natural que tais gentes [bárbaras] se submetam ao império de príncipes e nações mais cultas e humanas, para que, pelas suas virtudes e pela prudência das suas leis, abandonem a barbárie e submetam a uma vida mais humana e ao culto da virtude (GUINÉS, 1967, p. 85 apud DUSSEL, 2010, pág. 355, grifo do autor).

Pensando em trabalhos pedagógicos que viabilizem a formação crítica dos oprimidos e na consequente necessidade de construir propostas curriculares específicas que vão ao encontro das particularidades dos sujeitos da EJA, este projeto pretende buscar a aproximação dos sujeitos por meio de um processo de inclusão considerando os leitores como co-autores de propostas pedagógicas.

Nesse contexto, este trabalho objetivou produzir um documentário como opção metodológica que busca incluir a voz desses sujeitos em um material didático específico para a EJA. Por fim, essa proposta pode-se constituir como uma deliberação democrática que implica na construção de novos modelos de ensino para EJA.

\section{Metodologia}

Este trabalho foi caracterizado como um estudo de caso com o intuito de produzir um material didático inclusivo (MDI) de Química para o público da EJA utilizando um documentário como principal fonte de informações para o conteúdo do MDI.

Um dos aspectos considerados no direcionamento da pesquisa foi 0 significado produzido pelas pessoas que merece atenção especial do pesquisador, uma vez que a escolha das formas de produção dos dados baseou-se no enfoque das concepções dos participantes a respeito de alguns conceitos/significados que foram tratados no decorrer das gravações de conversas e da produção do documentário.

Contudo, para se ter um conhecimento prévio dos alunos no que se refere à vida pessoal, profissional e escolar e suas concepções de Ciência, optou-se em realizar um colóquio (quadro 1) na própria instituição para estabelecer o primeiro contato com os sujeitos da pesquisa. Para a realização do colóquio, planejou-se uma estrutura de discussão baseada na articulação entre três temas: Educação, Trabalho e Meio ambiente.

Quadro 1. Sistematização do Colóquio. 
Revista Tecné, Episteme y Didaxis: TED. Año 2014, Número Extraordinario. ISSN Impreso: 0121-3814, ISSN web: 2323-0126

Memorias, Sexto Congreso Internacional sobre Formación de Profesores de Ciencias. 08 al 10 de octubre de 2014, Bogotá

\section{Profesores de Ciencias. 08 a 10 de octubre de 2014 Bogotá}

\begin{tabular}{|c|c|c|}
\hline & Descriçc̃o & Objetiv os \\
\hline $1^{\circ}$ Momento & $\begin{array}{l}\text { Explicação e apontamentos a } \\
\text { respeito do PROEJA. }\end{array}$ & $\begin{array}{l}\text { Promover conhecimento a } \\
\text { respeito do programa. }\end{array}$ \\
\hline $2^{\circ}$ Momento & Dinâmica & $\begin{array}{l}\text { Quem começará } \\
\text { respondendo as perguntas } \\
\text { relacionadas a vida } \\
\text { escolare familiar. }\end{array}$ \\
\hline $3^{\circ}$ Momento & $\begin{array}{l}\text { Discussão do vínculo existente } \\
\text { entre educação, trabalho e meio } \\
\text { ambiente, } e \\
\text { apresentação do video "A } \\
\text { História do Trabalho", }\end{array}$ & $\begin{array}{l}\text { Que haja compreensão } \\
\text { deste vinculo: } \\
\text { Iniciar uma discussão sobre } \\
\text { a importância do trabalho } \\
\text { na vida humana; }\end{array}$ \\
\hline $4^{\circ}$ Momento & $\begin{array}{l}\text { Apresentação do video: O Ouro } \\
\text { Amarelo } \\
\text { Entrevista exibida no programa } \\
\text { Domingo Espetacular. Disponivel } \\
\text { em: http://r7.com/klzG }\end{array}$ & $\begin{array}{l}\text { Provocar a discussão a } \\
\text { respeito dos diferentes } \\
\text { aspectos envolvidos no } \\
\text { trabalho humano bem } \\
\text { como as condições } \\
\text { desumanas vivenciadas } \\
\text { em alguns trabalhos. }\end{array}$ \\
\hline $5^{\circ}$ Momento & INTERVALO & \\
\hline $6^{\circ}$ Momento & $\begin{array}{l}\text { Apresentação do video: A História } \\
\text { das coisas. } \\
\text { Documentário disponivel em: } \\
\text { watch? } v=7 \text { qFiGMS nNjw\& noredire } \\
\text { ct=1 }\end{array}$ & $\begin{array}{l}\text { Promover } \\
\text { conscientização do que } \\
\text { está acontecendo no } \\
\text { mundo perante a uma } \\
\text { sociedade consumista. }\end{array}$ \\
\hline $7^{\circ}$ Momento & $\begin{array}{l}\text { Explicações envolvendo Química } \\
\text { com os demais temas abordados } \\
\text { anteriormente }\end{array}$ & $\begin{array}{l}\text { Relacionar a Química com } \\
\text { o cotidiano do aluno. }\end{array}$ \\
\hline $8^{\circ}$ Momento & $\begin{array}{l}\text { Discussão sobre a importância da } \\
\text { educação. } \\
\text { Apresentação do video: Para } \\
\text { Quê Serve a Escola? } \\
\text { Documentário disponivel em: } \\
\text { watch? }=3 \mathrm{JZzSed} \text { SloM }\end{array}$ & $\begin{array}{l}\text { Provocar discussóes a } \\
\text { respeito do papel da } \\
\text { escola na vida de cada } \\
\text { um. }\end{array}$ \\
\hline $9^{\circ}$ Nomento & $\begin{array}{l}\text { Retorno à discussão sobre a } \\
\text { relação entre educação, } \\
\text { trabalho e meio ambiente. }\end{array}$ & $\begin{array}{llr}\text { Repetir a } & \text { pergunta } \\
\text { realizada } & \text { no } & \text { terceiro } \\
\text { momento. } & & \end{array}$ \\
\hline $10^{\circ}$ Nomento & Convite para o documentário & $\begin{array}{l}\text { Participação dos alunos no } \\
\text { documentário que } \\
\text { resultará em um material } \\
\text { didático, em que os } \\
\text { mesmos serão co- } \\
\text { produtores. }\end{array}$ \\
\hline $11^{\circ}$ Momento & ENCERRAMENTO & \\
\hline
\end{tabular}


Revista Tecné, Episteme y Didaxis: TED. Año 2014, Número Extraordinario. ISSN Impreso: 0121-3814, ISSN web: 2323-0126

Memorias, Sexto Congreso Internacional sobre Formación de Profesores de Ciencias. 08 al 10 de octubre de 2014, Bogotá

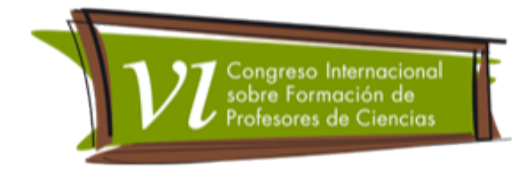

A realização do colóquio cumpriu o primeiro objetivo de apreender informações sobre a história dos indivíduos envolvidos na pesquisas que percorreram diferentes caminhos até voltar à escola. No entanto, dados que poderiam subsidiar a discussão de conceitos químicos de forma direta no documentário não foram observados. Para sistematizar a produção do documentário, elaborou-se um roteiro de perguntas (Quadro 2) que direcionasse os alunos na construção de conceitos fundamentais da Química a partir da historicidade desses sujeitos.

Quadro 2. Roteiro de produção do documentário.

P1- Qual é o seu nome?

P2- Conte um pouco de sua trajetória envolvendo aspectos da vida pessoal, do trabalho e da educação?

P3- No PROEJA você tem alguma disciplina que envolve o conhecimento da Ciência tais como a Biologia, Química e física?

P4- Você considera que a Ciência é importante na Educação para Jovens e Adultos? Por quê?

P5- Existem momentos diários que te faz lembrar-se de Ciência? Quais?

P6- Na sua casa ou no seu trabalho é possivel visualizar algum processo químico? Qual?

P7- Você utiliza alguma substância em sua alimentação e higiene pessoal? Dê exemplos.

P8- Como você acha que as substâncias são formadas?

P9- As substâncias podem ser consideradas como algo próprio da sociedade moderna e da vida acelerada nas cidades?

P10- Aponte fatos marcantes que ao longo da historia mostrem exemplos da relação entre o desenvolvimento da Química e as mudanças na vida das pessoas.

P1 1- O ambiente em que vivemos hoje pode ser considerado como o mesmo de antigamente? Qual o papel da indústria química nessas mudanças?

P12- Como as substâncias podem afe tar o equilibrio da natureza?

P13- Quais as consequências da poluição para a saúde humana?

P14- Para você o que é o enxofre?

P15- $O$ que seria uma ligação química?

P16- E concentração o que seria?

P17- Você já ouviu falar de pHę O que seria?

P18-Como seria possivel explicar uma reação química?

P19-Como são formados os vários materiais que compõe o nosso mundo? P20- O que você gostaria de aprender na disciplina de Química? 
Revista Tecné, Episteme y Didaxis: TED. Año 2014, Número Extraordinario. ISSN Impreso: 0121-3814, ISSN web: 2323-0126

Memorias, Sexto Congreso Internacional sobre Formación de Profesores de Ciencias. 08 al 10 de octubre de 2014, Bogotá

As perguntas não foram elaboradas para obter conceitos prontos e acabados, mas sim para apreender o que eles entendiam e conheciam a respeito dos temas propostos. Almejava-se identificar concepções próprias que não soassem palavras vazias e que eles pudessem transpor esses conhecimentos com o seu cotidiano, pois segundo Vygotski (1978) citado por Maldaner e Piedade (1995, pág. 16) "As palavras exercem a função de conceitos e podem servir como meio de comunicação muito antes de atingirem o nível de conceitos, característico do pensamento plenamente desenvolvido".

O documentário não pode ser considerado apenas como instrumento para coleta de dados iniciais do material didático, mas como mecanismo de comunicação capaz de promover troca de experiências.

Assim, apresentaremos no tópico abaixo que os dados do documentário podem contribuir essencialmente para a elaboração do material didático, pois através dele os alunos tiveram voz ativa, demonstrando suas concepções a respeito de conteúdos químicos e conseguiram fazer articulações entre os conceitos e questões socioambientais.

\section{Análise dos Resultados}

A análise do documentário possibilitou a construção de categorias representantes das falas dos sujeitos participantes a serem utilizadas na produção do MDI. A descrição das categorias apresenta os assuntos abordados pelos alunos da EJA no documentário. Esses assuntos serão selecionados como conteúdo do MDI. 
Revista Tecné, Episteme y Didaxis: TED. Año 2014, Número Extraordinario. ISSN Impreso: 0121-3814, ISSN web: 2323-0126

Memorias, Sexto Congreso Internacional sobre Formación de Profesores de Ciencias. 08 al 10 de octubre de 2014, Bogotá

Quadro 3. Descrição das categorias analisadas

\begin{tabular}{|c|c|}
\hline & Descrição \\
\hline $\begin{array}{l}\text { AFIRMAÇÂO DA } \\
\text { IMPORTANCIA DA } \\
\text { CIÊNCIA }\end{array}$ & $\begin{array}{l}\text { - Conhecimento para o cotidiano } \\
\text { - Ampliação do conhecimento } \\
\text { - Conhecimento para mudanças de atitudes } \\
\text { - Conhecimento do cotidiano }\end{array}$ \\
\hline $\begin{array}{l}\text { A CIÊNCIA NO } \\
\text { COTIDIANO }\end{array}$ & $\begin{array}{l}\text { - Relação ciência e religião } \\
\text { - Conhecimento da natureza } \\
\text { - Relação ciência e qualidade de vida } \\
\text { - Relação ciência e trabalho } \\
\text { - Relação ciência e vida. } \\
\text { - Riência imperceptível no cotidiano } \\
\text { - Relação ciência e informação }\end{array}$ \\
\hline $\begin{array}{l}\text { VISUALIZAÇAO DE } \\
\text { PROCESSO QUIMICO } \\
\text { E UTILIZAÇAO DE } \\
\text { PRODUTOS } \\
\text { QUIMICOS / } \\
\text { SUBSTÂNCIAS }\end{array}$ & $\begin{array}{l}\text { - Produtos de limpeza e higienização } \\
\text { - Relação processo e reação química } \\
\text { - Produtos químicos na produção de alimentos } \\
\text { - Relação processo químico e meio ambiente } \\
\text { - Processos químicos no trabalho } \\
\text { - Relação químico como material } \\
\text { - Re cosméticos }\end{array}$ \\
\hline $\begin{array}{l}\text { RELAÇAO ENTRE A } \\
\text { MUDANÇA DE VIDA } \\
\text { DAS PESSOAS COM A } \\
\text { INDÚSTRIA QUÍMICA }\end{array}$ & $\begin{array}{l}\text { - Relação da criação de produtos com a facilitação de vida para o ser } \\
\text { humano } \\
\text { - Descoberta de medicamentos/tratam entos } \\
\text { - Relação química e vida } \\
\text { - Consequências negativas das indústrias químicas } \\
\text { - Relação indústria química e aparelhos tecnológicos } \\
\text { - Geração de empregos }\end{array}$ \\
\hline $\begin{array}{l}\text { RELAÇAO ENTRE A } \\
\text { MUDANÇA DO MEIO } \\
\text { AMBIENTE COM A } \\
\text { INDÚSTRIA QUÍMICA }\end{array}$ & $\begin{array}{l}\text { - Problemas ambientais relacionados com a indústria química } \\
\text { - Relação da criação de produtos com a indústria química } \\
\text { - Problemas de saúde relacionados com as indústrias/produtos } \\
\text { químicos } \\
\text { - Descaso de indústrias químicas para com o meio ambiente } \\
\text { - Maleficios ou beneficios relacionados com as indústrias químicas } \\
\text { imperceptiveis. } \\
\text { - Desenvolvimento de atitudes corretas das indústrias com recursos } \\
\text { naturais } \\
\text { - Descaso do ser hum ano para com o meio ambiente } \\
\text { - Conscientização da química na vida do ser humano }\end{array}$ \\
\hline
\end{tabular}


Revista Tecné, Episteme y Didaxis: TED. Año 2014, Número Extraordinario. ISSN Impreso: 0121-3814, ISSN web: 2323-0126

Memorias, Sexto Congreso Internacional sobre Formación de Profesores de Ciencias. 08 al 10 de octubre de 2014, Bogotá

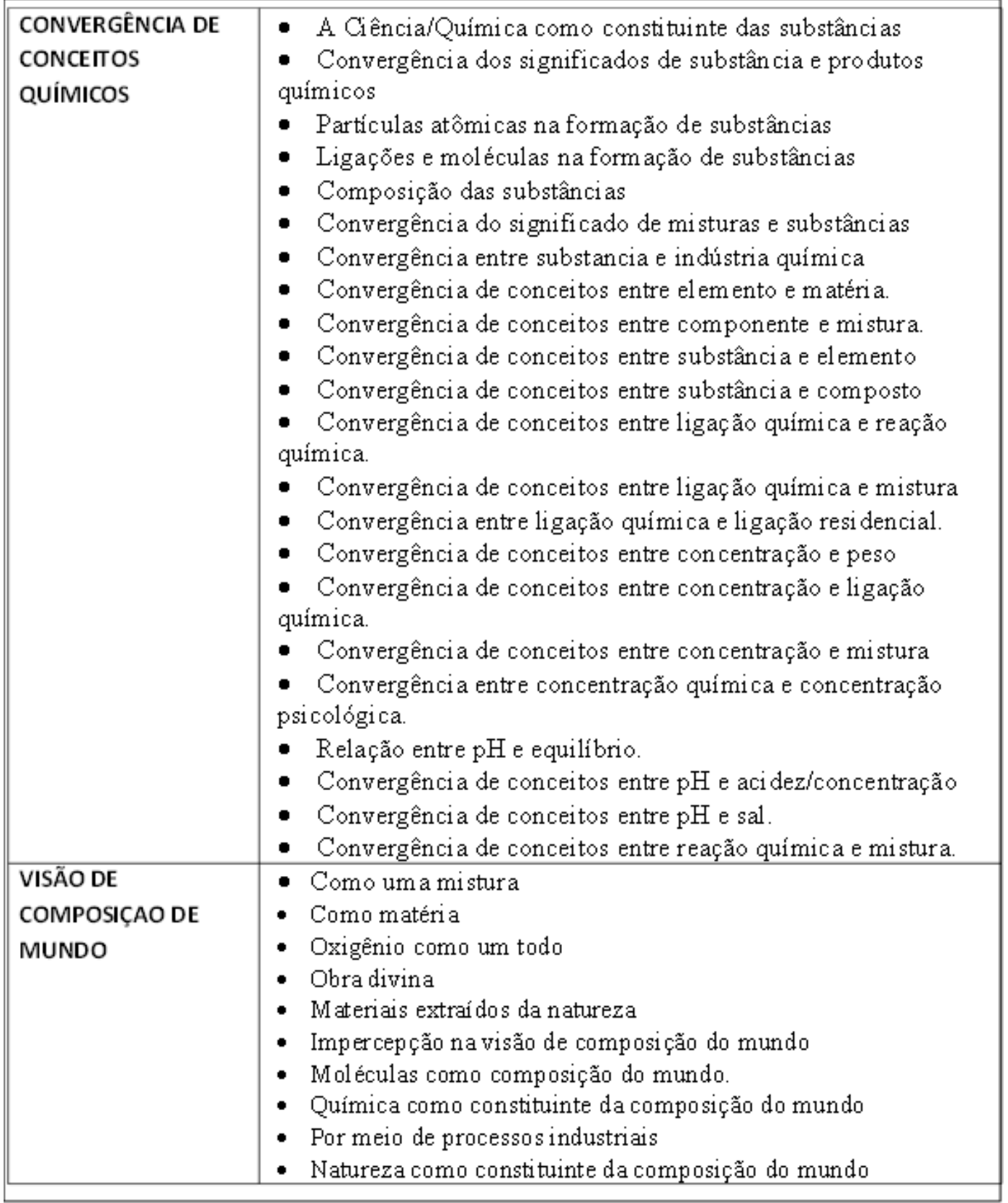

A primeira categoria "Afirmação da importância da ciência" está relacionada com a pergunta do bloco 4. Todos os alunos afirmaram a importância de estudar as ciências na EJA, ainda que tenha sido analisado a presença de diferentes níveis de importância, o que contribuiu para a identificação de diferentes elementos dentro da categoria em questão.

A segunda categoria "A ciência no cotidiano" está relacionada ao bloco 5, nesse os alunos são perguntados se existem momentos diários que os fazem 
Revista Tecné, Episteme y Didaxis: TED. Año 2014, Número Extraordinario. ISSN Impreso: 0121-3814, ISSN web: 2323-0126

Memorias, Sexto Congreso Internacional sobre Formación de Profesores de Ciencias. 08 al 10 de octubre de 2014, Bogotá

lembrar de ciência, pois entende-se que há a necessidade de sempre relacionar fatos do dia-a-dia dos alunos com a ciência.

Essa pesquisa propõe justamente a possibilidade de integração do conhecimento (realidade) do aluno com os conteúdos escolares, tentando diminuir a distância entre esses conhecimentos.

A terceira categoria "Visualização de processo químico e utilização de produtos químicos / substâncias" se relaciona com o bloco 6, onde os alunos falam sobre a visualização de processos químicos e a utilização desses.

A quarta categoria "Relação entre a mudança de vida das pessoas com a indústria química" está relacionada com bloco 10, esperava-se nessa categoria que os alunos apontassem fatos marcantes que ao longo da história demostrassem exemplos da relação entre o desenvolvimento da Química e as mudanças na vida das pessoas.

A quinta categoria "Relação entre a mudança do meio ambiente com a indústria química" está relacionada com os blocos 11, 12 e 13, pois essas questões falam a respeito do meio ambiente, os problemas que podem ser provocados pela indústria química além de problemas de saúde causados pela poluição oriunda dessas indústrias.

A sexta categoria "Convergência de conceitos químicos" engloba vários blocos, em todos os conceitos que os alunos convergiram, e não foram poucos por sinal, o que pode ser visto na tabela 1. Entre 8 diferentes conteúdos pode-se notar 91 convergências:

Tabela1. Demonstração de ocorrência de convergências de conceitos.

\begin{tabular}{|c|c|}
\hline $\begin{array}{c}\text { Conteúdos químicos } \\
\text { abordados }\end{array}$ & Convergências \\
\hline 8 & 91 \\
\hline
\end{tabular}

Com a análise foi possível perceber que os conceitos que mais geram convergências e dúvidas são: misturas e substâncias.

Ao apresentar no material didático as diferentes concepções que os alunos têm sobre os conceitos, pode-se notar que algumas convergências não acontecem somente com eles, mas com uma infinidade de outros alunos. No material propriamente dito, as falas desses alunos poderão aparecer em caixas de diálogo no começo de cada seção com o seguinte título: "O que o 
Revista Tecné, Episteme y Didaxis: TED. Año 2014, Número Extraordinario. ISSN Impreso: 0121-3814, ISSN web: 2323-0126

Memorias, Sexto Congreso Internacional sobre Formación de Profesores de Ciencias. 08 al 10 de octubre de 2014, Bogotá

aluno pensa!" para em seguida apresentar o conteúdo químico como pode ser visto na figura abaixo:

\section{O que o aluno pensa!}

Eu acho que elas são formadas, as substâncias, as substâncias são formadas por gases, (RISOS), álcool, açúcar (AP12).

Figura 1. Caixa de dialogo

A sétima e última categoria "Visão de composição do mundo" está relacionada ao bloco 19, que investiga como os alunos acham que são formados os diferentes materiais que compõe nosso mundo, há nessa categoria como em todas as outras as diferentes visões de composição do mundo até a impercepção dessa visão.

Com as unidades de análise foi possível perceber que os alunos às vezes têm medo de falar o que pensam sobre determinados conteúdos, sendo que em muitas vezes esses alunos conhecem fenômenos e reações presentes no seu cotidiano e no seu trabalho, isso pode ocorrer, pois para se profissionalizarem, não necessitam do conhecimento de conceitos científicos.

Essa proposta caracteriza-se como material de inclusão/participação desses alunos, onde terão espaço para manifestar suas concepções acerca dos conceitos científicos por meio de suas falas. Dessa forma, o desenvolvimento de trabalhos a partir de contextos levam ao surgimento de questionamentos que ampliam as possibilidades da construção de conhecimento juntamente com alunos e professor.

\section{Considerações finais}

O trabalho buscou desenvolver uma metodologia para elaboração de MDI, pois é notória a necessidade de criar propostas metodológicas includentes, visto que há uma deficiência nesse quesito para o público da EJA. Trata-se de uma iniciativa voltada para a construção de um modelo diferenciado que pode servir como estímulo ou desenho primário para novas elaborações e assim por diante, propondo uma nova história em que esses alunos sejam atores fundamentais no processo ensino-aprendizagem.

Conclui-se ainda que a produção de documentário que busca apreender concepções, valores e conhecimentos prévios dos estudantes da EJA quando questionados sobre alguns conceitos químicos, possibilita o desenvolvimento 
Revista Tecné, Episteme y Didaxis: TED. Año 2014, Número Extraordinario. ISSN Impreso: 0121-3814, ISSN web: 2323-0126

Memorias, Sexto Congreso Internacional sobre Formación de Profesores de Ciencias. 08 al 10 de octubre de 2014, Bogotá

de sistema de informações iniciais de conceitos a serem trabalhados em MDI pela problematização das falas dos próprios leitores. Assim, as falas dos alunos/participantes tornaram-se um elemento de análise muito importante possibilitando o diálogo problematizador entre os sujeitos participantes da pesquisa.

A elaboração de propostas de ensino que integram problematização dos saberes cotidianos com conhecimento científico, constitui um meio diferente de apropriação do conhecimento, pois ao problematizar sobre quaisquer temas ampliam-se as possibilidades de reflexão sobre os mesmos, principalmente se for algo perceptível para esses alunos, portanto, as compreensões sobre conteúdos químicos, questões sociais e históricas favorecem outras visões de mundo.

As análises mostraram que há possibilidade de elaboração de um material didático utilizando o conteúdo de um documentário.

Enfim, para utilização de documentário na elaboração de um material didático que considere e inclua as concepções de jovens e adultos trabalhadores, se faz necessário entender que o currículo escolar não pode ser considerado como uma programação pronta e acabada, mas que esteja em permanente reconstrução, levando em consideração a diversidade de culturas e as diferentes formas de pensar.

\section{Referências bibliográficas}

Dussel, E. (2005). Filosofia da libertação: crítica à ideologia da exclusão. $3^{a}$ ed. São Paulo: Paulus.

Dussel, E. (2010). Meditações anticartesianas sobrea origem do antidiscurso filosófico da modernidade. In SANTOS, B. de S.; MENEZES, M. P.(Orgs). Epistemologia do Sul. São Paulo: Cortez.

Freire, P. (201 1). Pedagogia do oprimido. (50 ed). Rio de janeiro: Paz eTerra.

Lüdke, M.\& André, Marli E. D. A. (2008). Pesquisa em educação: abordagens qualitativas. ( $11^{a}$ reimpressão). São Paulo: EPU.

Santos, B. de S. (2010). Para além do pensamento abissal: das linhas globais a uma ecologia de saberes. In Santos, B. de S.; MENEZES, M. P.(Orgs). Epistemologia do Sul. São Paulo: Cortez. 